\title{
A GESTÃO AMBIENTAL APOIADA POR INDICADORES DE CUMPRIMENTO DAS NORMAS AMBIENTAIS: A VISÃO DOS DIFERENTES SEGMENTOS SOCIAIS*
}

\author{
Maria do Carmo Bezerra \\ Silvia Capelli
}

\begin{abstract}
RESUMO
O tema indicadores de aplicação e cumprimento da norma ambiental vem despertando cada vez mais 0 interesse dos gestores públicos em suas ações de avaliar a eficácia das normas de proteção ao meio ambiente. É um grande desafio em função das dificuldades geradas pela inexistência de precedentes, escassa bibliografia e, em especial, da farta legislação ambiental e a distribuição de competências para legislar entre todos os entes da federação brasileira.
\end{abstract}

O presente trabalho parte de um estudo mais amplo que definiu indicadores para os recursos naturais de água, ar e vegetação, e utilizou a metodologia denominada Enforcementand Compliance Indicators - ECE, desenvolvida pela Rede Internacional para Aplicação e Cumprimento da Norma Ambiental INECE, explicitada no documento INECE-OECD Workshop on Environmental Compliance and Enforcement Indicators: Measuring What Matters. Destaca um dos aspectos relevantes na definição de indicadores, a percepção dos diferentes segmentos sociais sobre sua a importância de sua definição e implementação.

Consolida a consulta realizada no âmbito do CONAMA - Conselho Nacional do Meio Ambiente, em 2004, sobre a adoção da metodologia e confirma a idéia inicial sobre a necessidade de ordenamento das informações de gestão ambiental, de forma estruturada e com possibilidade de acompanhamento temporal para que se constituam em um instrumento efetivo da retro-alimentação das politicas públicas e do cumprimento das normas ambientais.

Palavras-chave: Indicadores Ambientais, Gestão Ambiental, Política Ambiental

\section{ABSTRACT}

The study field of the environment regulation compliance and establishment of indicators is becoming more attractive within public authorities in terms of evaluation of environmental protection regulation efficacy. It consists in a big challenge in terms of mitigation of difficulties related to the non-existing predecessors, the lack of bibliography available and, in special, the fact of the number of environmental regulation and of policy makers among every single branch of the Brazilian Government.

This essay is part of a major study that has defined indicators to be used to monitor the water natural resources, air and vegetation and has used the Enforcement and Compliance indicators - ECE, developed by the International Network for Environmental Compliance and Enforcement - INECE, within the document INECE-OECD Workshop on Environmental Compliance and Enforcement Indicators: Measuring What Matters. This essay highlights one of the most important aspects on the definition of those indicators, and the perception from the different social groups on their definition and implementation.

This aims to consolidate the issue raised by CONAMA - Conselho Nacional de Meio-Ambiente (Environmental National Council), on 2004, about the adoption of this methodology and provide confirmation of the initial concept about the need of environment data ordering in a structured way with the possibility of timing monitoring in order to became in a effective tool for public policies data collection and organization and the environmental regulation compliance.

Keywords: Ambient Indicators, Ambient Management, Ambient Politics

\footnotetext{
* Artigo parcialmente apresentado no $10^{\circ}$ Congresso Brasileiro de Direito Ambiental, realizado pelo Instituo Direito por um Planeta Verde, São Paulo-SP, julho de 2005, parcialmente publicado nos anais em forma de CDROM e papel. Sobre o tema, também foi ministrada uma palestra no seminário de avaliação do uso de indicadores de cumprimento das normas ambientais na América Latina, realizado pela CEPAL- Comissão Econômica da América Latina e Caribe das Nações Unidas em, Santiago do Chile, abril de 2006.
} 


\section{INTRODUÇÃO}

A partir da década de 1980, a maioria dos paises da América Latina experimentou mudanças significativas na incorporação da dimensão ambiental ao processo de desenvolvimento, expressas na construção de um amplo aparato de normas ambientais e na criação de instituições públicas responsáveis por sua implementação.

Neste período, a gestão ambiental no Brasil adquiriu statusdeprioridadenaagendanacional.Aconsciência da sociedade sobre o meio ambiente, bem como os mecanismos de participação democrática se ampliaram, resultando na mobilização em favor da eficácia da legislação ambiental.

A legislação brasileira em matéria ambiental é extensa e abrangente. Há vários aspectos que são foco de legislação específica, como os recursos ambientais :ar, água, solo, flora e fauna. Poluição e ecossistemas também se inscrevem na pauta desses temas específicos. Além dessa tutela especial sobre os bens ambientais, há legislação que trata da tutela constitucional, administrativa e processual do meio ambiente. Entretanto, a despeito de todo esse aparato jurídico e administrativo, o Brasil não se sobressai como exemplo de preservação de suas riquezas naturais ou culturais.

Contrariando as expectativas em face a nossa base legal, torna-se cada vez mais perceptivel a tensão entre as evidências de deterioração da qualidade ambiental e a ineficácia da resposta gerada pelo arcabouço jurídico e institucional estabelecido. Em decorrência, despontam a inexistência de mecanismos estruturados e objetivos que permitam, ou pelo menos auxiliem, a avaliação da implementação e do cumprimento da regulamentação ambiental e de seus resultados concretos.

Um dos aspectos que configura a fragilidade da gestão ambiental está, com certeza, na ausência de informação organizada sobre a qualidade dos recursos naturais.

De fato, é impossivel planejar ações voltadas para a melhoria da qualidade ambiental, sem dispor, por um lado, de um conhecimento sistematizado sobre a evolução da qualidade dos recursos naturais, e, por outro lado, sem estabelecer indicadores de desempenho dos programas ambientais implementados de acordo com a legislação.

$\mathrm{Na}$ gestão ambiental brasileira o monitoramento é o instrumento de controle e avaliação que tem como intuito conhecer o estado e as tendências qualitativas e quantitativas dos recursos naturais $e$ as influências exercidas pelas atividades humanas e por fatores naturais sobre o meio ambiente. Reflete ainda, o resultado da atuação das instituições responsáveis por planos, programas, projetos, instrumentos legais e financeiros capazes de manter o equilibrio ecológico ou de recuperar áreas e sistemas específicos.

Implantar, portanto, atividades de monitoramento ambiental requer uma seleção prévia de indicadores. A ausência desses indicadores representa um dos pontos frágeis da implementação da política ambiental no Brasil, uma vez que é inexpressiva a experiência em avançar e retro-alimentar políticas públicas com base em processos de avaliação de desempenho.

Vale salientar que as análises por meio de indicadores vêm ganhando peso nas metodologias utilizadas para resumir a informação de caráter técnico e científico, permitindo que a informação seja mais facilmente utilizável por tomadores de decisão, gestores, políticos, grupos de interesse ou pelo público em geral.

0 incremento de indicadores ambientais e de desenvolvimento sustentável iniciou-se no final da década de 1980, no Canadá e em alguns países 
da Europa, mas seu grande impulso ocorreu a partir da aprovação da Agenda 21, na Conferência das Nações Unidas sobre Meio Ambiente realizada no Rio de Janeiro em 1992'.

A definição de indicadores como hoje firmada no panorama internacional, quer sejam ambientais, quer sejam de sustentabilidade, encontra-se em fase de construção no Brasil nos moldes da experiência internacional, com seus primeiros resultados obtidos a partir de meados dos anos 1990. Assim, ao tempo em que se sistematizam as informações existentes, busca-se lançar as bases para a prática de um monitoramento orientado por indicadores que correlacionem causas e efeitos em matéria de qualidade ambiental.

Deve-se ressaltar, por um lado, que a utilização de indicadores $e$ indices não consiste em uma abordagem pacífica, pois as simplificações efetuadas na aplicação das metodologias geram, na maior parte das vezes, várias controvérsias. Por outro lado, as eventuais perdas (ou descontinuidade) de informação têm constituído um entrave à adoção de forma generalizada e consensual dos sistemas de indicadores e índices.

A formulação de indicadores pressupõe a disponibilidade de informações e dados confiáveis e comparáveis num determinado período de tempo. Esse é o principal desafio , iniciar uma série histórica aponta caminhos para a identificação de parâmetros que ao longo do tempo conduzam à averiguação do cumprimento e da eficácia das normas ambientais.

No atinente ao papel dos atores sociais no cumprimento da legislação, a aplicação da lei normalmente envolve diferentes segmentos, que incluem os diferentes níveis de governo, cidadãos, organizações não governamentais e o setor produtivo, dentre os principais.

Qualquer ação cidadã será dificultada, ou mesmo impossibilitada, se os atores interessados não tiverem acesso à informação sobre potenciais irregularidades ou violações das normas ambientais.
Informações relevantes incluem desde relatórios sobre a qualidade ambiental, até registros sobre infrações e autuações lavradas pelos órgãos públicos.

O presente trabalho utiliza indicadores denominados Enforcement and Compliance Indicators - ECE, a partir da metodologia desenvolvida pela Rede Internacional para Aplicação e Cumprimento da NormaAmbiental-INECE, explicitada no documento INECE-OECD Workshop on Environmental Compliance and Enforcement Indicators: Measuring What Matters ${ }^{2}$.

Aqui se destaca um dos aspectos, a percepção do s diferente segmentos sociais sobre a implementação de indicadores de cumprimento das normas ambientais, abordados no âmbito do Projeto Piloto de aplicação da metodologia (2004-2005) desenvolvido pelo Instituo Direto por um Planeta Verde e apoiado pelo Instituto do Banco Mundial e CEPAL O Projeto Piloto foi também aplicado a outros paises da América Latina, espelhando, 0 estudo a troca de idéias e experiências com os demais participantes como a FARN, da Argentina e CelBA, do México - bem como dos subsídios colhidos nas reuniões promovidas pela INECE/ OECD em Paris (2003) e pela CEPAL, em Santiago do Chile (2004).

\section{AS BASES PARA ADOÇÃO DE INDICADORES NA GESTÃO AMBIENTAL BRASILEIRA}

Dispomos hoje de farta e avançada legislação ambiental no Brasil. A implementação dessa legislação, entretanto, é prejudicada por diferentes fatores de ordem política, social, administrativa e econômica. Torna-se cada vez mais perceptivel a ineficácia da resposta do arcabouço legal e institucional às evidências de deterioração da qualidade ambiental.

O Brasil ainda não possui indicadores de aplicação e cumprimento da norma ambiental. De outro lado, 
a publicidade, a participação popular e o acesso público e gratuito à informação são expressamente garantidos pela Constituição Federal $^{3}$ e pela Lei da Política Nacional do Meio Ambiente ${ }^{4}$, que prevê a obrigatoriedade de o poder público manter um sistema nacional de informações sobre o meio ambiente, elaborar relatório de qualidade e prestar informações relativas ao meio ambiente, produzindoas, quando inexistentes.

A Lei Federal $n^{0}$ 10.650, de 16 de abril de 2003, dispõe sobre o acesso público a informações e dados existentes nos órgãos integrantes do Sistema Nacional de Meio Ambiente - SISNAMA, obrigando os órgãos e entidades da Administração Pública direta, indireta e fundações a permitir o acesso público aos documentos, expedientes e processos administrativos que tratem de matéria ambiental e a fornecer todas as informações ambientais que estejam sob sua guarda, em meio escrito, visual, sonoro ou eletrônico, especialmente as relativas a:

I. qualidade do meio ambiente;

II. políticas, planos e programas potencialmente causadores de impacto ambiental;

III. resultados de monitoramento e auditoria nos sistemas de controle de poluição e de atividades potencialmente poluidoras, bem como de planos e ações de recuperação de áreas degradadas;

IV. acidentes, situações de risco ou de emergência ambientais;

V. emissões de efluentes líquidos e gasosos e produção de resíduos sólidos;

VI. substâncias tóxicas e perigosas;

VII. diversidade biológica;

VIII. organismos geneticamente modificados.

O prazo para ser fornecida a informação ou garantida a consulta ao processo administrativo, resguardados os sigilos industrial, comercial e financeiro ${ }^{5}$, é de trinta dias. As informações são prestadas mediante o recolhimento de valor do dispêndio para o seu fornecimento, observadas as normas e tabelas específicas fixadas pelo órgão competente em nível federal, estadual ou municipal ${ }^{6}$.

Porém, a ausência de mecanismos estruturados e objetivos que permitam a avaliação da aplicação e do cumprimento da legislação ambiental, bem como de seus resultados na qualidade do meio ambiente é problema cuja solução deve ser urgente, a fim de manter a mobilização da sociedade por uma melhor qualidade de vida.

\section{SOBRE INDICADORES}

A CEPAL $^{7}$, no estudo denominado Indicadores de Sostenibilidad Ambiental y de Desarrollo Sostenible: Estado del Arte y Perspectivas (2001), menciona que um dos principais desafios para o desenvolvimento de indicadores consiste na complexidade de seu delineamento.

Existem várias definições de "indicadores". São "ferramentas constituidas por uma ou mais variáveis que, associadas através de diversas formas, revelam significados mais amplos sobre os fenômenos a que se referem" ou "uma medida quantitativa ou qualitativa que é usada para demonstrar modificações ou para simplificar a informação, servindo para entender e valorizar fenômenos complexos".

Tradicionalmente, os indicadores relacionados ao meio ambiente podem ser divididos em ${ }^{10}$.

-"Indicadores Ambientais: podem representar 0 estado do ambiente (que não é o mesmo que sustentabilidade ambiental), ou quanto existe de um recurso natural e qual é a sua qualidade. Isso não necessariamente indica que essa quantidade de vegetação ou essa qualidade de água seja sustentável. E ainda que seja sustentável, segue sendo um indicador ambiental válido;

-Indicadores de Sustentabilidade: querem mostrar uma mudança temporal na capacidade de manter 
ou de aumentar;

-Indicadores de Desenvolvimento Sustentável: querem representar um progresso no: desempenho do desenvolvimento (exemplo: diminuição da pobreza) e - na sustentabilidade do desenvolvimento"11.

\subsection{Os indicadores $\mathrm{ECE}^{12}$}

A presente comunicação é um resumo da consulta realizada no âmbito do Projeto Piloto acima referido sobre a percepção dos diferentes atores sociais sobre a importância e viabilidade de aplicação de indicadores para verificar o cumprimento das normas ambientais no Brasil. É importante destacar que o referido trabalho partiu do teste de uma metodologia específica, qual seja: a metodologia ECE.

Enforcementand Compliance Indicators - ECE, é uma metodologia desenvolvida pela Rede Internacional para Aplicação e Cumprimento da Norma Ambiental - INECE, explicitada no documento INECE-OECD Workshop on Environmental Compliance and Enforcement Indicators: Measuring What Matters ${ }^{13}$.

A OECD ${ }^{14}$ define "cumprimento" como a resposta comportamental a exigências regulatórias que asseguram a proteção da saúde humana e do ambiente. Similarmente, a Environment Canada define "cumprimento" como um estado de conformidade com a lei. Assim, indicadores de cumprimento incluem as evidências mensuráveis sobre a resposta de indivíduos submetidos a exigências regulatórias.

A OECD conceitua "fiscalização" como a aplicação de todas as ferramentas disponiveis para a obtenção / concreção do cumprimento da exigência legal. Sob o ponto de vista amplo, essa definição inclui promoção e monitoramento do cumprimento ou da desobediência. Indicadores de fiscalização incluem aquelas evidências que fornecem informações sobre o desempenho de esforços fiscalizadores, ou seja, promoção e monitoramento do cumprimento, de respostas desajustadas.

Os indicadores ECE podem ser divididos em:

-Indicadores de Entrada - relacionam-se a recursos (pessoas, dinheiro) aplicados em diferentes operações (por exemplo, número de agentes de fiscalização). Apesar de sua utilidade limitada, indicam a expressão governamental de compromisso, tornando-se importantes para a determinação da eficiência e do retorno do investimento, quando conciliadas a outros tipos de indicadores

-Indicadores de Saída - são medidas quantitativas e qualitativas de atividades, produtos de trabalho ou ações. Em programas de fiscalização ambiental um exemplo de indicador de saída seria o número de autos de infração aplicados ou acordados anualmente. Saidas geralmente contabilizam resultados produzidos pelos recursos da agência ou do programa. Indicadores de entrada e de saída relacionam-se a ações sobre as quais o governo detém controle direto.

-Indicadores de Resultado - Classificam-se em três ordens:

-Indicadores de Resultado Imediato - relacionamse à mensuração do efeito imediato daqueles que foram atingidos pelos indicadores de saida;

-Indicadores de Resultado Intermediário - medem o progresso no alcance de resultados finais, tais como mudanças de comportamento, conhecimento ou condições que resultem de atividades programáticas. Tais alterações estão associadas com o resultado final, ou são necessárias para este.

-Indicadores de Resultado Final - mensuram os resultados derradeiros para os quais um dado programa fora concebido. A melhora na condição atmosférica ou da qualidade da água são exemplos de resultados finais, que são geralmente onerosos e sofrem influências de inúmeras forças. Assim, 
é bastante difícil usá-los como indicadores de programas de cumprimento e fiscalização.

\subsection{Finalidade dos indicadores ECE}

Em geral, Indicadores de Aplicação e Cumprimento Ambientais (ECE) servem a três propósitos distintos:

-Auxiliar no gerenciamento de programas e em operações de monitoramento, de fiscalização e de cumprimento. Para operações de monitoramento, os indicadores precisarão ser focados nas saídas (outputs), provendo uma contagem do número de atividades que estejam sendo conduzidas num determinado período de tempo.

- Melhorar a capacidade de prestação de contas de programas de fiscalização. Tais indicadores são utilizados no relato de resultados para autoridades orçamentárias centrais, corporações legislativas que exercem funções de fiscalização e de dotação lalocação de verbas, grupos constituintes que participam efetivamente de questões de proteção ambiental e público em geral. Indicadores relacionados a saídas (outputs) revelam a extensão de atividades implementadas, e indicadores relacionados a resultados (outcome) mostram os resultados obtidos ou os efeitos daquelas atividades.

- Avaliar o desempenho de programas de aplicação e cumprimento, contribuindo para a melhoria do desempenho. Auxiliar gerentes de programas a distinguirem o que está do que não está funcionando, bem como a determinar o que precisa ser modificado para atingir o desempenho almejado e previamente estipulado. Para muitos, o aperfeiçoamento de programas consiste no objetivo mestre dos indicadores de desempenho, sendo a razão máxima para o investimento em seu desenvolvimento e em seu uso.

\section{PROCESSO DE CONSULTA REALIZADA AOS DIFERENTES SEGMENTOS SOCIAIS SOBRE A APLICAÇÃO DE INDICADORES DE CUMPRIMENTO DAS NORMAS AMBIENTAIS.}

A aplicação de normas ambientais envolve diferentes atores sociais, dentre eles, organismos de governo, grupos de cidadãos, organizações não governamentais e o setor produtivo privado que desempenham papéis diferenciados em sua formulação, aplicação, cumprimento e fiscalização.

Para a definição da estratégia de elaboração de um sistema de indicadores para avaliar a aplicação e cumprimento das normas ambientais fez-se necessário averiguar a motivação e os meios de que dispõem cada um desses atores para aplicar $e$ cumprir as normas, bem como o grau de interação, de modo a identificar o impacto dessas condições sobre a qualidade ambiental.

Algumas questões teóricas nortearam a elaboração do Projeto Piloto bem como a consulta que terá aqui seus resutlados apresentados:

- Os indicadores de aplicação e cumprimento de normas ambientais constituem-se em instrumento ainda não adotado no país, sendo sua relevância indiscutível para o aprimoramento da gestão ambiental vis-à-vis da experiência internacional sobre a aplicação dessa metodologia

-A experiência brasileira em matéria de desenvolvimento de indicadores ambientais ainda se encontra incipiente, com iniciativas de construção de indicadores por parte de alguns órgãos públicos, como antes referido, não incorporadas à tomada de decisões sobre políticas públicas ou na gestão ambiental. Decorre dai a pertinência da elaboração de um Projeto Piloto para que seja possível verificar a aplicabilidade e efetividade em um processo contínuo de melhoria da gestão ambiental;

- $\mathrm{processo} \mathrm{de} \mathrm{construção} \mathrm{de} \mathrm{indicadores} \mathrm{deve}$ 
contar com a participação de diferentes segmentos da sociedade, organizados em diversas instâncias, num sistema de checagem contínua, retroalimentada por atores relevantes.

\subsection{Universo de aplicação da pesquisa}

Identificou-se, como atores relevantes para a implementação do Projeto Piloto, o Ministério Público e o Poder Executivo, por meio dos órgãos ambientais, nos três niveis de governo. Ademais, com relação à pesquisa, ainda foram considerados atores relevantes o setor produtivo privado, os órgãos não-ambientais e a sociedade civil organizada.

Por envolver todos os atores relevantes, elegeuse 0 Conselho Nacional do Meio Ambiente ${ }^{15}$ como destinatário da consulta do Projeto Piloto.

\subsection{Critérios de elaboração e aplicação dos questionários}

As perguntas foram formuladas de modo a se obter informações sobre a percepção dos atores com relação aos aspectos importantes na definição dos indicadores de aplicação e cumprimento de normas ambientais nas etapas de entrada, saída e resultado.

Um conjunto de perguntas de caráter geral foi elaborado para ser aplicado aos diferentes grupos representados no CONAMA de modo a possibilitar uma avaliação comparativa da pesquisa sobre a percepção desses diferentes grupos naquilo que diz respeito às relações entre normas ambientais $\mathrm{e}$ qualidade ambiental. O Projeto Piloto possuía como foco as normas ambientais relativas aos termas : ar, água e vegetação

Denominou-se "critério" alguns aspectos considerados pelos especialistas como recorrentes na maioria dos diagnósticos realizados sobre gestão ambiental no País e que também encontram eco na experiência internacional. A averiguação de sua incidência torna-se importante para a definição de indicadores de aplicação e cumprimento das normas ambientais, uma vez que podem estar relacionados a estes aspectos, a eficácia na implementação e 0 cumprimento de normas ambientais que se venha aferir com a aplicação do Projeto Piloto.

Além disso, é importante destacar que a adoção deste enfoque na elaboração do questionário tem como premissa que a adoção de qualquer tipo de indicador se constitui na possibilidade de intervir de forma propositiva na melhoria da gestão ambiental.

Os aspectos tratados de forma sistemática na elaboração dos questionários foram:

-Processo de elaboração da norma: analisar se as normas em matéria de ar, água e vegetação são suficientemente claras e conduzem à aplicação eficiente e eficaz na obtenção da qualidade ambiental;

-Disponibilidade de informação: analisar a qualidade das informações existentes nas instituições responsáveis pela aplicação e cumprimento das normas, para conhecer sua qualidade e possibilidade de disponibilização em prol de uma gestão ambiental eficiente e eficaz nos temas propostos;

-Estratégia de implementação: analisar as condições de uma efetiva política ambiental nos órgãos responsáveis pelo cumprimento e aplicação das normas. Se existem planos definidos como programas, metas a alcançar etc.

- Capacitação: analisar as condições de capacitação dos aplicadores e formuladores de normas ambientais. A habilitação de funcionários e agentes que aplicam as normas tem sido considerada uma necessidade generalizada nos países da América Latina, não sendo diferente no Brasil. Há predominância de conhecimentos atomizados que não remetem à necessária interdisciplinaridade da gestão ambiental o que resulta em interpretação e 
aplicação limitadas dos objetivos das normas.

Em função da diversidade dos segmentos de que é composto o CONAMA, foram elaborados questionários específicos para: (I) sociedade civil organizada e executivo federal não ambiental; (II) órgãos governamentais de meio ambiente nos quatro níveis; (III) setor privado; (IV) Ministério Público Estadual e Federal ${ }^{16}$.

O questionário foi organizado com um bloco de perguntas comuns a todos os segmentos, relativas à percepção dos entrevistados sobre a importância do uso de indicadores que tratassem sobre a clareza e relevância das normas, além dos meios para sua implementação - aí inclusa a capacitação. Outros dois blocos de perguntas visavam receber insumos para a definição de indicadores de entrada e saída a partir do papel específico de cada um dos segmentos consultados. Um quarto bloco, também comum a todos os segmentos, tratou sobre indicadores de resultado.

\subsection{Resultados da consulta}

Foram distribuídos a todos os 108 conselheiros, obtendo-se um retorno de apenas $21 \%$, com destaque para os segmentos dos empresários e Ministério Público, obteve-se $100 \%$ de retorno. No sentido oposto, com órgãos ambientais e sociedade civil organizada se obteve respectivamente $15 \%$ e $36 \%$ de retorno.

A tabulação dos dados permite algumas inferências sobre 0 entendimento dos segmentos para os critérios que presidiram a elaboração da consulta destacando-se:

\section{I-Sobre as perguntas comum a todos os segmentos}

O objetivo das perguntas era verificar: a disposição para definição e aplicação de indicadores ambientais; a visão dos diferentes segmentos quanto aos beneficios (de preservação ambiental) obtidos com o cumprimento das normas ambientais; se os segmentos dispõem de meios e se consideram conhecedores e capacitados para cumprir ou fiscalizar as normas ambientais. Foi aplicado a todos os segmentos de modo a proceder a uma avaliação comparativa.

A primeira conclusão relevante para o Projeto Piloto diz respeito ao reconhecimento da importância da definição de indicadores: $100 \%$ dos entrevistados declararam que a definição de um sistema de indicadores favorece a eficácia no cumprimento de normas ambientais.

A análise comparativa identificou que $70 \%$ dos entrevistados dizem possuir programas ambientais internos em suas organizações. Entretanto, apenas $13 \%$ declaram possuir programas de capacitação para cumprirem as normas ambientais.

Por outro lado, $60 \%$ dos empresários e $25 \%$ dos órgãos ambientais reconhecem não existir conhecimento técnico nos órgãos ambientais para o cumprimento das normas.

Sobre a relação causal entre a existência de normas ambientais e melhoria da qualidade do ambiente, a maioria dos empresários (90\%) declara não haver relação. Foram destacados os seguintes motivos: falta de fundamentação científica no estabelecimento das normas (50\%); e inexistência de relatórios de qualidade ambiental que as avaliem ( $40 \%)$.

Em sentido oposto, a totalidade das entidades da sociedade civil e órgãos não-ambientais declararam que percebem relação entre a existência de normas e a melhoria da qualidade ambiental - afirmando, desta forma, acreditar no sistema de formulação das normas ambientais no pais. Já entre os órgãos ambientais, executores e participantes de sua formulação, apenas $50 \%$ declaram existir essa relação, apontando a ausência de relatórios de qualidade ambiental para seu monitoramento.

A análise acerca da objetividade e clareza das normas indicou que os representantes do Ministério 
Público, em sua totalidade interpretam que as normas são claras e objetivas. Os outros segmentos, em contraposição, têm opinião diversa: $62 \%$ dos representantes da sociedade civil e órgãos não ambientais, $75 \%$ dos órgãos ambientais e $90 \%$ dos empresários vêem como grandes dificuldades no cumprimento das normas: a subjetividade que gera margem a interpretações díspares, a inexistência de campanhas de esclarecimento sobre os objetivos a serem alcançados e a ausência de conhecimento para sua aplicação por parte dos quadros técnicos (implementadores e cumpridores).

Quando perguntados sobre os procedimentos adotados para cumprimento das normas, 100\% dos empresários e membros do Ministério Público, $62 \%$ das ONGs e $75 \%$ dos órgãos ambientais reconhecem a inexistência de procedimentos técnicos e administrativos claros e transparentes por parte dos órgãos ambientais para o cumprimento das normas. As razões para tanto dizem respeito, em especial, à ausência de informações técnicas e de capacitação para determinar tais processos.

A percepção dos diferentes segmentos sobre os meios e a capacidade instalada nas diferentes instituições envolvidas na aplicação e cumprimento das normas também é diferenciada. Enquanto $100 \%$ dos membros do Ministério Público e $80 \%$ dos empresários indicaram que se sentem capacitados e que dispõem de meios financeiros e técnicos, além de uma estratégia de atuação para implementação e cumprimento das normas, os demais apresentam situações diferenciadas:

a) As ONGs e órgãos não ambientais apontam as seguintes ausências: recursos humanos (75\%), recursos financeiros (60\%) e capacitação (50\%);

b) Os órgãos ambientais, por sua vez, manifestaram um indice de $50 \%$ de reconhecimento sobre suas dificuldades de cumprimento das normas ambientais para cada um dos itens acima referidos capacitação, disponibilidade de recursos humanos e financeiros e estratégia de atuação).
As figuras a seguir ilustram os resultados obtidos com o Bloco 1 de questões, que tratou de avaliar a percepção dos diferentes atores sobre a relação entre a qualidade ambiental e o cumprimento das normas.

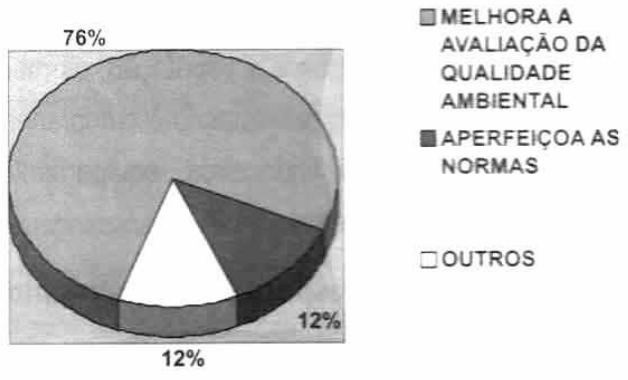

Figura 01: A importância da definição de indicadores Fonte: Instituto "O Direito por um Planeta Verde" 2005:61

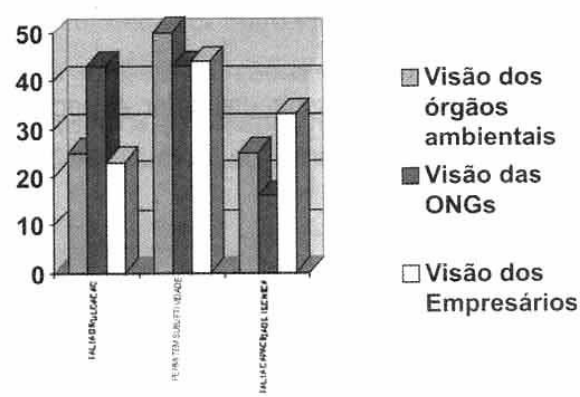

Figura 02: A falta de objetividade e clareza das normas Fonte: Instituto "O Direito por um Planeta Verde" 2005:62

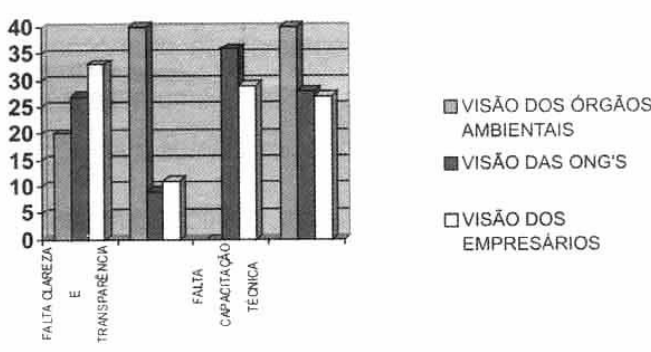

Figura 03: Razões da inadequabilidade entre os procedimentos técnico-administrativos e os objetivos das normas ambientais

Fonte: Instituto "O Direito por um Planeta Verde" 2005:62 


\section{II - Indicadores de entrada na percepção dos órgãos ambientais, Ministério Público e empresários}

Oobjetivodasperguntas, deabordagensdiferenciadas , era identificar indicadores de entrada, conforme definido na metodologia ECE adotada pelo Projeto Piloto, ou seja, as normas mais representativas em relação ao ar, a água e a vegetação, os meios existentes para sua implementação e cumprimento relativo aos recursos financeiros, equipamentos, capitação e conhecimento.

\section{II.1 - Avaliação das respostas dos empresários}

O segmento manifestou uma auto-avaliação de sua disposição e de seus instrumentos e meios para cumprimento das normas ambientais extremante satisfatória, sugerindo a viabilidade de adoção de alguns indicadores de entrada para avaliação do segmento em relação ao cumprimento de normas ambientais:

- $70 \%$ declaram possuir um setor especíico para tratar do cumprimento de normas ambientais e proteção ambiental;

•60\% manifestaram possuir mecanismos de participação social na execução de suas políticas ambientais;

- $100 \%$ declararam possuir registro com classificação de riscos ambientais sobre insumo de produção;

• $80 \%$ manifestaram possuir programa de capacitação de seus empregados em temas ambientais;

.90\% dizem possuir programas de promoção de tecnologias mais limpas em suas empresas e que este processo tem ocorrido nos últimos 5 anos;

- $80 \%$ declararam que suas políticas ambientais vão além do cumprimento de normas ambientais, avançando para programas voluntários de certificação.

\section{II.2 - Avaliação das respostas dos órgãos ambientais e Ministério Público}

As perguntas foram feitas em relação aos recursos humanos e financeiros, processo de informatização de rotinas, procedimentos técnicos e administrativos e a relação entre estes e a percepção da qualidade ambiental.

A maior diferenciação entre os dois segmentos diz respeito à disponibilidade de procedimentos informatizados. O Ministério Público declara possuir $100 \%$ dos procedimentos informatizados (termos de ajustamento de conduta firmados, inquéritos civis instaurados, notificações e acompanhamentos de Ações Civis Públicas).

Em relação aos órgãos ambientais, apenas $50 \%$ das rotinas administrativas são informatizadas, sendo 0 restante realizado manualmente.

Um quarto dos órgãos ambientais declara não possuir procedimentos técnicos operacionais, enquanto outros $25 \%$ declaram possuí-los, sendo que destes, apenas a metade está informatizado. Esses procedimentos dizem respeito ao número de ações de fiscalização realizadas, autos de infração emitidos, número de licenciamentos para atividades potencialmente poluidoras emitidos e monitoramentos efetivados.

As perguntas referentes aos recursos financeiros disponiveis revelaram a dificuldade em se estabelecer uma relação entre o cumprimento de normas especificas para os recursos naturais de ar, água e vegetação, e a evolução dos orçamentos dos órgãos, pois estes são elaborados por rubricas gerais. Ainda sobre o tema, registra-se que a alocação de recursos tem se mantido estável para $100 \%$ do Ministério Público e para apenas 25\% dos órgãos ambientais. Por outro lado, para $25 \%$ dos órgãos ambientais, a alocação de recursos financeiros tem sido decrescente.

Ainda foi perguntado sobre a forma como poderiam os meios disponiveis para o cumprimento das 
normas (indicadores de entrada) refletirem a qualidade ambiental (indicadores de resultado). Os resultados, organizados por recurso natural, apontaram os seguintes indicadores:

-Para ar: monitoramento da qualidade do ar no que se refere à poluição industrial;

-Para água: monitoramento das condições de balneabilidade das águas, controle de lançamento de efluentes urbanos e implementação de comitês de bacia hidrográfica;

-Para vegetação: incremento do número de área verde por habitante e do número de unidades de conservação por unidade da federação.

\section{III - Indicadores de saída na percepção dos órgãos ambientais, Ministério Público e empresários}

O objetivo das perguntas elaboradas de acordo com as especificidades do segmento era identificar os indicadores de saída, conforme definido na metodologia ECE adotada pelo Projeto Piloto, ou seja, as informações que indicam o grau de cumprimento das normas, seja do ponto de vista do órgão implementador (autos de infração emitidos e fiscalizações realizadas) ou do cumpridor (notificações atendidas, multas pagas, etc).

\section{III.1 - Avaliação das respostas dos empresários:}

As informações prestadas pelo segmento são relevantes para a definição de indicadores de saida, quando $80 \%$ declararam que suas empresas possuem informações sistematizadas. Segundo os empresários, esses dados estão disponíveis para dar a sociedade e órgãos ambientais sobre seu nivel de cumprimento de normas e de medidas mitigadoras adotadas para os impactos ambientais negativos de suas atividades.

Sobre os temas de ar, água e vegetação acreditam na sua participação na melhoria da qualidade ambiental: $70 \%$ consideram que têm contribuído para melhoria da qualidade do ar, $80 \%$ da água,
$50 \%$ para reduzir o desmatamento e $60 \%$ para incrementar o reflorestamento.

As perguntas permitiram a manifestação simultânea em relação aos diferentes recursos naturais.

Em relação às razões que levam o segmento a cumprir as normas, $60 \%$ informaram que se trata de cumprir a lei, não tendo aparecido como relevante a força da fiscalização exercida pelos órgãos ambientais (mencionada por apenas $4 \%$ como motivo).

A responsabilidade social aparece com $6 \%$, a certificação ambiental com $17 \%$ e a melhoria da imagem do produto com $13 \%$ entre as principais razões que levam o empresariado a cumprir normas ambientais (figura 04).

Perguntados de forma direta se o cumprimento de normas ambientais melhora a imagem do produto, $80 \%$ dos empresários manifestaram que sim e para $20 \%$ é indiferente. Por outro lado, questionados se as normas ampliam mercados, $50 \%$ afirmaram que sim e outros $40 \%$ acreditam que restringem (figuras 05 e 06).

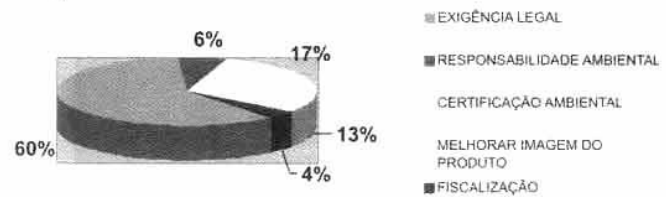

Figura 04: Motivação dos empresários para 0 cumprimento das normas ambientais

Fonte: Instituto "O Direito por um Planeta Verde" 2005:65

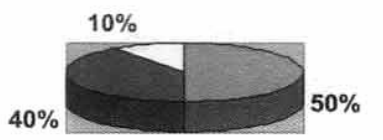

$$
\begin{aligned}
& \text { - AMPLIAM MERCADOS } \\
& \text { RESTRINGEM } \\
& \text { MERCADOS } \\
& \text { DINDIFERENTE }
\end{aligned}
$$

Figura 05: Cumprimento das normas ambientais e mercados

Fonte: Instituto "O Direito por um Planeta Verde" 2005:66

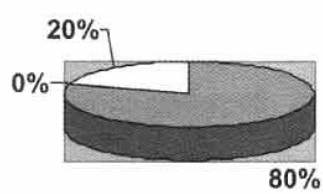

$$
\begin{aligned}
& \text { - A IMAGEM DO } \\
& \text { PRODUTO MELHORA } \\
& \text { - A IMAGEM DO } \\
& \text { PRODUTO NÃO } \\
& \text { MELHORA } \\
& \text { 口NĀO HÁ RELAÇÃO }
\end{aligned}
$$

Figura 06: Relação entre o cumprimento das normas e a imagem do produto

Fonte: Instituto "O Direito por um Planeta Verde" 2005:66 


\section{II.2 - Avaliação das respostas dos órgãos ambientais e Ministério Público}

O Ministério Público, conforme já havia se manifestado em outras respostas, afirma possuir seus procedimentos $100 \%$ informatizados. Entretanto não dispõe de informações sistematizadas sobre 0 cumprimento de normas especificas. 0 que existe diz respeito a informaçōes sobre os atos de sua competência - como número de TACs ${ }^{19}$, notificações, inquéritos civis instaurados e acompanhamento de $\mathrm{ACPs}^{18}$.

Quanto aos órgãos ambientais, as perguntas neste bloco visavam identificar os principais instrumentos utilizados para implementar o cumprimento das normas ambientais nos temas ar, água e florestas e se elas estavam em condições de serem disponibilizadas - tendo em vista a implementação do Projeto Piloto. (vide Tabela 01)

\section{IV - Indicadores de resultados na percepção dos órgãos ambientais, Ministério Público e empresários}

De modo análogo aos anteriores, esse bloco objetivava colher subsidios para a definição dos indicadores de resultado, aqueles referentes à melhoria da qualidade ambiental.

As respostas dos três segmentos permitem uma análise comparativa onde desponta uma percepção negativa sobre a melhoria da qualidade ambiental do Pais. A totalidade (100\%) manifesta sua visão de que tanto 0 ar como a água e o desmatamento vêm agravando sua qualidade ambiental nos últimos 5 anos. A visão dos órgãos ambientais difere e posiciona-se num patamar de $50 \%$ para os três temas.

Os empresários, por sua vez, possuem uma percepção mais otimista e diferenciada em relação aos temas: $50 \%$ acreditam que a qualidade do ar vem melhorando, $70 \%$ com relação à água e $60 \%$ sobre a redução do desmatamento.

Quando perguntados sobre como seria possivel verificar estas afirmações, os entrevistados apontam quais os possiveis indicadores de resultados conforme Tabela 02.

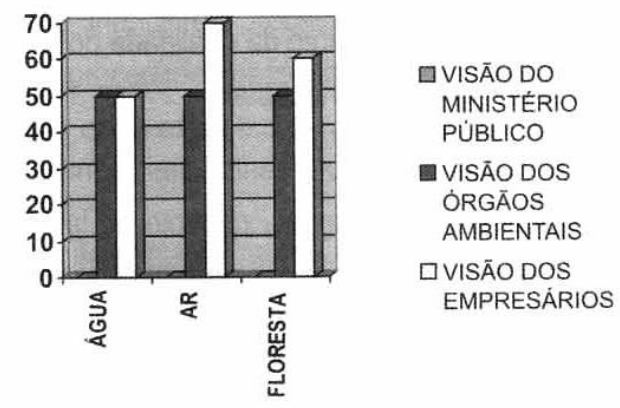

Figura 07: Melhoria da qualidade ambiental nos últimos 5 anos.

Fonte: Instituto "O Direito por um Planeta Verde" -

2005:69. 
Tabela 01: Principais instrumentos indicados para implementar o cumprimento de normas por recurso natural

\begin{tabular}{|c|c|c|c|}
\hline & ÁGUA & AR & COBERTURA VEGETAL \\
\hline $\begin{array}{l}\text { Principais } \\
\text { procedimentos } \\
\text { técnicos } \\
\text { identificados na } \\
\text { consulta }\end{array}$ & $\begin{array}{l}\text { - Emissäo de outorga } \\
\text { - Licenciamento de } \\
\text { atividades } \\
\text { - Planos de bacia } \\
\text { hidrográfica }\end{array}$ & $\begin{array}{ll}\text { - } & \text { Número de } \\
\text { fiscalizações } \\
\text { procedidas } \\
\text { - } \\
\text { Autos de infraçāo } \\
\text { emitidos } \\
\text { Mediçōes da rede de } \\
\text { qualidade do ar } \\
\text { (automática e } \\
\text { manual) }\end{array}$ & 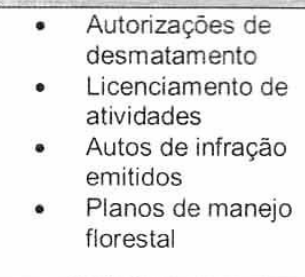 \\
\hline
\end{tabular}

Fonte: Indicadores de Aplicação e Cumprimento da Norma Ambiental para Ar, Água e Vegetação no Brasil. Instituto "O Direito por um Planeta Verde" - 2005:67.

Tabela 02: Indicadores da qualidade ambiental

\begin{tabular}{|c|c|c|c|}
\hline Hict & ÁGUA & AR & COBERTURA VEGETAL \\
\hline \multirow{2}{*}{$\begin{array}{l}\text { MINISTÉRIO } \\
\text { PÚBLICO } \\
\text { ÓRGÃOS } \\
\text { AMBIENTAIS }\end{array}$} & $\begin{array}{c}\text { - Indice de tratamento } \\
\text { dos efluentes }\end{array}$ & $\begin{array}{l}\text { - Indice de crescimento } \\
\text { industrial }\end{array}$ & - Taxa de desmatamento \\
\hline & $\begin{array}{l}\text { - Indicadores de } \\
\text { potabilidade e } \\
\text { balneabilidade }\end{array}$ & $\begin{array}{l}\text { - Material particulado, } \\
\mathrm{CO}_{2}, \mathrm{CO} \text { e O }\end{array}$ & $\begin{array}{l}\text { - Taxa de } \\
\text { desmatamento, } \\
\text { recuperação de } \\
\text { áreas degradadas } \\
\text { e } \\
\text { - Indice de proteção das } \\
\text { APP. }\end{array}$ \\
\hline \multirow[t]{2}{*}{ EMPRESÁRIOS } & $\begin{array}{l}\text { - Indicadores de } \\
\text { potabilidade e } \\
\text { - Indice de proteção das } \\
\text { APP }\end{array}$ & $\begin{array}{l}\text { - Material particulado, } \\
\mathrm{CO}_{2}, \mathrm{CO} \mathrm{e} \mathrm{O}_{3}\end{array}$ & $\begin{array}{l}\text { - Indice de } \\
\text { reflorestamento }\end{array}$ \\
\hline & & $\begin{array}{r}100 \\
80 \\
60 \\
40 \\
20\end{array}$ & $\begin{array}{l}\text { 口VISÃO DO } \\
\text { MINISTÉRIO } \\
\text { PÚBLICO } \\
\text { VISÃO DO ÓRGĀO } \\
\text { AMBIENTAL } \\
\text { प VISÃO DOS } \\
\text { EMPRESÁRIOS }\end{array}$ \\
\hline
\end{tabular}

Figura 08: Melhoria da articulação entre os agentes intervenientes na gestão ambiental

Fonte: Instituto "O Direito por um Planeta Verde" 2005:70. 
A consulta procurou por fim, averiguar a percepção dos diferentes segmentos em relação ao grau de articulação entre eles e que elementos poderiam indicar uma condição de evolução nessa matéria. Nesse sentido, a avaliação aponta visões bem diferenciadas. Enquanto 100\% dos membros do Ministério Público e 30\% dos empresários acreditam que a articulação tem piorado, $100 \%$ dos órgãos ambientais e $60 \%$ dos empresários acreditam que tem melhorado. Por fim, $10 \%$ dos empresários dizem não ter condições de avaliar.

Os principais elementos destacados como indicadores de melhoria da articulação dizem respeito ao aumento do número de acordos e convênios de cooperação técnica, às parcerias em programas ambientais e à adesão voluntária a certificação ambiental. Apesar de o Ministério Público não haver se manifestado sobre esta pergunta, tanto os órgãos ambientais quanto os empresários citam os TACs - Termos de Ajustamento de Conduta - como um indicador de parceria e acordo.

\section{CONSIDERAÇÕES FINAIS}

Em que pese o universo de retorno dos questionários $(21 \%)$, os resultados alcançados corroboram, em sua maioria, o entendimento que a equipe técnica já possuia sobre 0 assunto e permitiu uma maior clareza e legitimidade para definição dos indicadores de entrada, saida e resultado apresentados no Projeto Piloto. A percepção dos diferentes atores envolvidos na gestão é dispares e estas percepções ocorrem sem fundamentação em dados objetivos.

A consulta permitiu confirmar a necessidade de ordenamento das informações de gestão ambiental, de forma estruturada e com possibilidade de acompanhamento temporal pra que se constituam em um instrumento efetivo da retro-alimentação das políticas públicas e do cumprimento das normas ambientais. O RQMA - Relatório de Qualidade do
Meio Ambiente, previsto na legislação ambiental brasileira (Lei 6938/81), se destaca como o instrumento capaz de fornecer amparo para esta necessidade da gestão ambiental.

Aqui vale destacar as conclusões gerais a que se chegou com o Projeto Piloto que podem ser resumidas da seguinte forma:

O processo de elaboração do Projeto Piloto possibilitou neste periodo de um ano e três meses de seu desenvolvimento, a identificação e articulação de diversas iniciativas que vêm ocorrendo no Brasil para o estabelecimento de indicadores ambientais. É bem verdade que os maiores esforços encontramse concentrados em indicadores para aferição da sustentabilidade das políticas públicas no marco do que vem sendo promovido pela CDS-ONU e PNUMA.

A proposta de uma metodologia de indicadores que possibilite aferir o grau de implementação da norma ambiental, a partir da qualidade dos recursos naturais, foi muito bem recebida pelos diferentes segmentos da sociedade, como demonstra a consulta realizada no âmbito do Projeto.

Dada a descentralização na gestão do meio ambiente no Brasil, decorrente de seu modelo federativo, é possivel verificar uma grande quantidade de informaçöes dispersas nos diversos órgãos ambientais estaduais e municipais. Essas informações, porém, nem sempre são cotejáveis, em razão das disparidades regionais, que se refletem na quantidade e confiabilidade dos dados disponiveis diante da assimetria institucional entre esses órgãos.

Também se percebeu, ao longo do estudo, a clara necessidade de se desenvolver um sistema de indicadores voltados à aferição da implementação da legislação de meio ambiente, já que os poucos indicadores desenvolvidos no País, até agora, dizem respeito à sustentabilidade.

Concluiu-se que 0 grande mérito da metodologia 
ECE é ser um potencial instrumento para a aferição da eficácia da norma ambiental e de sua capacidade de alterar a qualidade ambiental nas três esferas de aplicação do Direito: administrativa, civil e penal.

Verificou-se, por exemplo, da resposta aos questionários encaminhados ao CONAMA, que apenas $4 \%$ do empresariado responderam cumprir a norma ambiental em decorrência da fiscalização exercida pelos órgãos de meio ambiente. Assim é muito provável que um futuro sistema de indicadores ECE que venha a ser aplicado no Brasil conclua pela necessidade de incentivos a esse cumprimento, além do já tradicional comando e controle. Também poderá concluir que uma norma pode ser aplicada não somente pelo esforço de seus agentes implementadores, mas, por exemplo, dever-se à melhoria de tecnologia do processo fabril.

Do ponto de vista técnico, o Projeto Piloto possibilitou a identificação de uma estrutura de gestão ambiental descentralizada no âmbito dos Estados, dispondo de informações sobre parâmetros previstos nas normas que podem ser traduzidos como indicadores de implementação, desde que organizados em um sistema de entrada, saida e resultado, como propõe a metodologia ECE.

Essa constatação permite afirmar ser praticável um Projeto de Indicadores de Aplicação e Cumprimento das Normas Ambientais com caráter nacional. Para tanto, faz-se necessária uma definição no âmbito federal, sobre o desenho do Programa de Indicadores e a articulação dos gestores ambientais estaduais para que as informações existentes sejam sistematizadas e disponibilizadas em forma de rede e com apoio de sistema informatizado.

\section{REFERÊNCIAS}

ALEXY, Robert. Teoria de los Derechos Fundamentales. Madrid: Centro de Estudios Constitucionales, 1997. p. 49.

BRASIL. Constituição, 1988. Constituição da República Federativa do Brasil, de 05 de outubro de 1988. 34. ed. São Paulo: Saraiva, 2004. 346 p.
BRASIL. Lei n. 6.938, de 15 de agosto de 1981. Dispõe sobre a Política Nacional do Meio Ambiente, seus fins e mecanismos de formulação e aplicação, e dá outras providências. In: Coletânea de Legislação Ambiental. Porto Alegre: Procuradoria-Geral de Justiça, 2003. p. 1317.

FARIAS, José Leite. Competência Federativa e Proteção Ambiental, Porto Alegre: Sergio Fabris, 1999. p. 113

INECE GLOSSARY. Common Definitions for ECE Terminology. Disponivel em: <http://inece.org/ indicators/glossary/glossary1.php>. Acesso em: 2004.

CAPPELLI, Sílvia. Atuação extrajudicial do Ministério Público na tutela do meio ambiente. In: Soares Júnior, Jarbas; Galvão, Fernando (Orgs.). Direito Ambiental: na visão da Magistratura e do Ministério Público. Belo Horizonte: Del Rey, 2003. 616 p. p. 243-278.

INECE-OECD Workshop on Environmental Compliance and Enforcement Indicators: Measuring What Matters. 2003. Paris, França. Proceedings... 3-4 november. 2003. Disponivel em: <http://inece. org/IndBackPaper.pdf>. Acesśo em: dez. 2004.

M., RAYÉN QUIROGA. Indicadores de Sostenibilidad ambiental y de Desarrollo Sostenible: Estado del Arte y Perspectivas. n. 16. Chile: Naciones Unidas: Serie Manuales, Septiembre 2000. 116p.

INECE. Environmental Compliance and Enforcement Indicators: Measuring What Matters. Background paper. In: INECE-OECD Workshop on Environmental Compliance and Enforcement Indicators: Measuring What Matters, Paris, France, 2003. Disponivel em: $<$ http://inece.org/IndBackPapel.pdf> Acesso em: 2005.

Instituto Direito por um Planeta Verde, Indicadores de Aplicação e Cumprimento da Norma Ambiental para Ar, Água e Vegetação no Brasil, Porto alegre, 2005.

STAHL, Micheal; FARREL, Robbi. Performance Measurement Guidance for Compliance and Enforcement Practitioners. Draft 1. In: Expert Working Group on Environmental Compliance and Enforcement Indicators, International Network for Environmental Compliance and Enforcement. EPA - U.S. Environmental Protection Agency.

STAHL, Micheal. Performance Indicator for Environmental Compliance and Enforcement Programs: The U.S. EPA Experience. In: INECEOECD Workshop on Environmental Compliance and Enforcement Indicators: Measuring What Matters, Paris, France, 2003. Proceedings... Disponivel em: $\quad<h t t p: / / i n e c e . s e r v e r b o x . n e t / i n d i c a t o r s /$ proceedings/04_us.pdf>. Acesso em: jan. 2005. 18 
p.

MINISTÉRIO DO MEIO AMBIENTE. Agenda 21 Brasileira: resultados da Consulta Nacional, Comissão de Políticas de Desenvolvimento Sustentável e da Agenda 21 Nacional. 2. ed. Brasilia: Meio Ambiente, 2004. Disponivel em: <http:/l www.mma.gov.br/estruturas/ agenda21/_arquivos/ consulta2edicao.pdf>. Acesso em: fev. 2005. p. 47.

\section{NOTAS}

1 De acordo com M., RAYÉN QUIROGA. Indicadores de Sostenibilidad Ambiental y de Desarrollo Sostenible: Estado del Arte y Perspectivas. n. 16. Chile: Naciones Unidas: Serie Manuales, Septiembre 2000. 116p.

${ }^{2}$ INECE. Environmental Compliance and Enforcement Indicators: Measuring What Matters. Background paper. In: INECE-OECD Workshop on Environmental Compliance and Enforcement Indicators: Measuring What Matters, Paris, France, 2003. Disponivel em: <http://inece.org/ IndBackPapel.pdf> Acesso em: 2005.

${ }^{3}$ Ibid., arts. $5^{\circ}$, XXXIII; 37 e 225, parágrafo $1^{\circ}$, IV.

${ }^{4}$ Lei Federal $n^{0} 6.938 / 81$.

${ }^{5}$ Lei Federal $n^{\circ} 10.650 / 03$, art. $2^{\circ}$, parágrafos $2^{\circ}$ e $5^{\circ}$.

${ }^{6}$ Lei Federal $n^{\circ} 10.650 / 03$, art. $9^{\circ}$.

${ }^{7}$ Comisión Económica para América Latina y el Caribe, órgão da ONU, com sede em Santiago do Chile, sítio da CEPAL, disponivel em: < http://www.eclac.cl/>.

${ }^{8}$ IBGE. Indicadores de Desenvolvimento Sustentável: Brasil 2004. Coordenação de Recursos Naturais e Estudos Ambientais. Rio de Janeiro: IBGE, 2004. 393 p.

${ }^{9}$ Glossário do foro de indicadores da INECE, disponivel em: <http://www.inece.org>, Indicator definition by United Nations Population Fund and EEA glossary.

${ }^{10}$ Informe de la reunión de consulta sobre Indicadores de Desarrollo Sostenible, CEPAL, Santiago, Chile, 7-9 de Octubre de 2003, p. 8.

${ }^{11}$ ibidem. 0 documento refere que a literatura demonstra confusão na definição dos indicadores porque muitas vezes se define como indicador de desenvolvimento sustentável ou de sustentabilidade um indicador de desempenho como, por exemplo, o nivel de pobreza ou o produto bruto.

12 Tradução livre do texto INECE. Environmental Compliance and Enforcement Indicators: Measuring What Matters. Background paper. In: INECE-OECD Workshop on Environmental Compliance and Enforcement Indicators: Measuring What Matters, Paris, France, 2003. Disponivel em: <http://inece.org/IndBackPapel.pdf> Acesso em: 2005. Realizada pelo colaborador Luciano Köche Huber.
${ }^{13}$ INECE. Environmental Compliance and Enforcement Indicators: Measuring What Matters. Background paper. In: INECE-OECD Workshop on Environmental Compliance and Enforcement Indicators: Measuring What Matters, Paris, France, 2003. Disponivel em: <http://inece.org/ IndBackPapel.pdf> Acesso em: 2005.

\section{Organization for Economic Co-operation and Development}

${ }^{15} \mathrm{O}$ CONAMA possui 108 membros com representação de cinco grandes setores: Governo Federal, governos estaduais, governos municipais, setor produtivo e sociedade civil organizada.

${ }^{16}$ Os modelos dos questionários não serão aqui apresentados em função de sua extensão. Mas encontram-se na integra na publicação do trabalho denominado: Indicadores de Aplicação e Cumprimento da Norma Ambiental para Ar, Água e Vegetação no Brasil, CEPAL/Planeta Verde , Porto Alegre, 2007.

${ }^{17}$ Termo de Ajustamento de Conduta.

${ }^{18}$ Ação Civil Pública. 